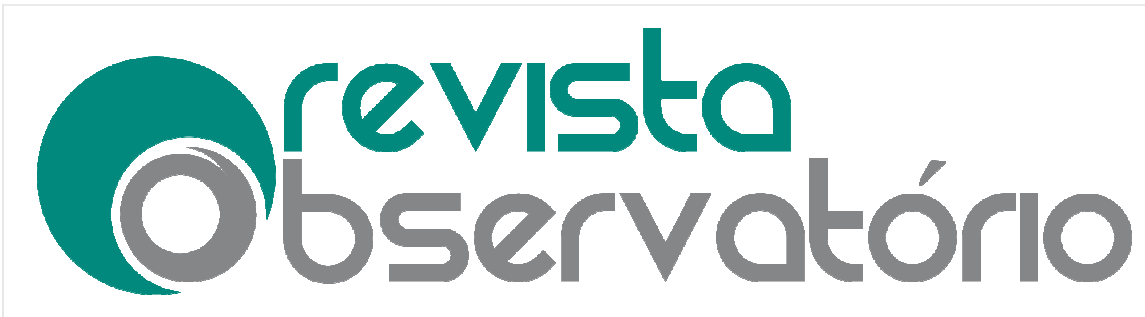

ISSN n² 2447-4266

Vol. 1, n 1, Maio-Agosto. 2015

DOI: http://dx.doi.org/10.20873/uft.2447-4266.2015v1n1p18

\section{A teoria e a prática do jornalismo investigativo: Uma análise das reportagens premiadas da Agência Pública}

The theory and the practice of investigative journalism: An analysis of the awarded reports Public Agency

La teoría y la práctica del periodismo de investigación: Un análisis de los informes ganadoras de la Agencia Pública

\author{
Paula Melani Rocha ${ }^{1}$ \\ Mariana Galvão Noronha ${ }^{2,3}$
}

\title{
RESUMO
}

O artigo tem como proposta analisar os saberes teóricos e práticos que envolvem o jornalismo investigativo e sua prática no Brasil. A discussão analisa as quatro reportagens premiadas da Agência Pública em 2014, exclusivamente de autoria feminina. O referencial teórico utilizado pauta-se em deontologias do jornalismo, jornalismo investigativo e métodos de apuração. Escolheu-se a Agência Pública pelo pioneirismo de sua proposta no Brasil.

Palavras-Chave: Jornalismo Investigativo; Métodos de Apuração em Jornalismo investigativo; Agência Pública.

\section{ABSTRACT}

\footnotetext{
${ }^{1}$ Doutora e mestre em Ciências Sociais pela Universidade Federal de São Carlos (UFSCAR). Graduada em Jornalismo pela Faculdade Cásper Líbero e em Ciências Sociais pela Universidade de São Paulo (USP). Professora da Pós-graduação em Jornalismo da Universidade Estadual de Ponta Grossa. Professora do curso de Jornalismo da mesma instituição. Pesquisadora colaboradora do LabJor/UNICAMP. E-mail:pmrocha@uepg.br.

${ }^{2}$ Mestranda em Jornalismo no Programa de Pós-Graduação da Universidade Estadual de Ponta Grossa. Graduada em Jornalismo pela mesma instituição. E-mail: pauteira.maria@gmail.com. 3 Endereço de contato (por correio): Universidade Estadual de Ponta Grossa. Mestrado em Jornalismo. Campus Uvaranas - Av. General Carlos Cavalcanti, 4748 - Ponta Grossa (PA), Brasil. CEP 84030-900.
} 


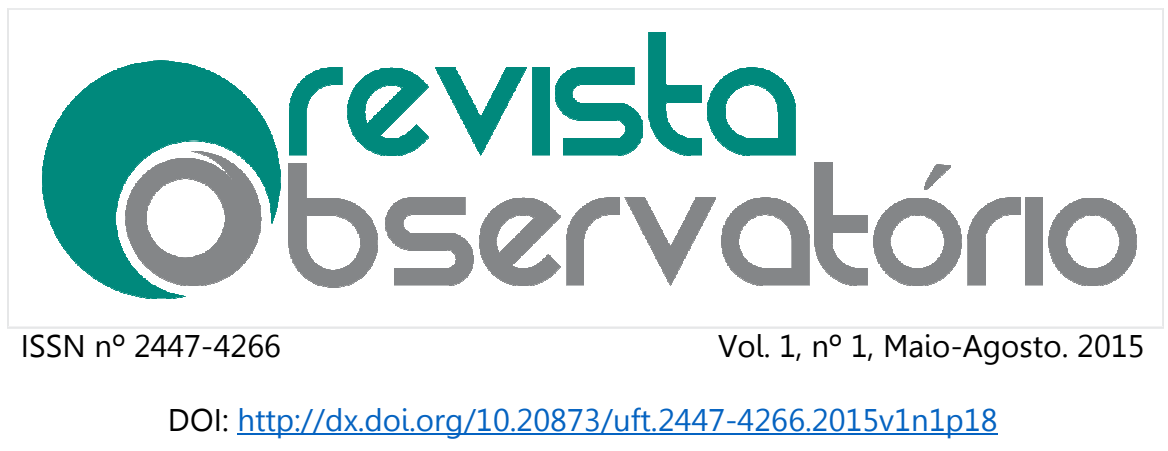

The article aims to analyze the theoretical and practical knowledge involving investigative journalism, its theoretical and methodological knowledge and practice in Brazil. The discussion analyzes the four reports awarded the Public Agency in 2014, exclusively female authors. The theoretical framework is based on deontology of journalism, investigative reporting and verification methods. We picked up the Public Agency for pioneering its proposal in Brazil.

Keywords: Investigative Journalism; Verification Methods in Investigative Journalis; Public Agency.

\section{RESUMEN}

El artículo tiene como objetivo analizar los conocimientos teóricos y prácticos que implica el periodismo de investigación y su práctica en Brasil. La discusión analiza los cuatro informes otorgados a la Agencia Pública de 2014, exclusivamente autoras mujeres. El marco teórico está en la deontología del periodismo, el periodismo de investigación y métodos de verificación. Recogimos la Agencia Pública por ser pionero en su propuesta en Brasil.

Palabras clave: Periodismo de Investigación; Metodos de Investigación; Agencia Publica.

Recebido em: 13/08/2015. Aceito em: 29/08/2015. Publicado em: 30.09.2015. 


\section{Obsevisto \\ ISSN n² 2447-4266 \\ Vol. 1, n 1, Maio-Agosto. 2015 \\ DOI: http://dx.doi.org/10.20873/uft.2447-4266.2015v1n1p18}

\section{Considerações iniciais sobre as especificidades do jornalismo investigativo}

$\mathrm{O}$ artigo analisa o conhecimento em jornalismo investigativo, seus saberes teórico-metodológicos e sua prática, neste sentido a discussão se debruça sobre quatro reportagens da Agência Pública premiadas em 2014, todas de autoria feminina. A reflexão é parte do projeto de mestrado que pesquisa a participação feminina no jornalismo investigativo brasileiro e a metodologia de investigação das reportagens, desenvolvido junto ao Programa de Pós-Graduação em Jornalismo da Universidade Estadual de Ponta Grossa (UEPG). O aporte teórico utilizado envolve deontologias do jornalismo, jornalismo investigativo e métodos de apuração. $\mathrm{O}$ artigo busca identificar as especificidades investigativas nas reportagens analisadas a partir da classificação das fontes utilizadas no processo de construção do texto.

Escolheu-se a Agência Pública pelo pioneirismo de sua proposta no Brasil, fundada em 2011, ela tem como escopo o jornalismo investigativo e a produção de reportagens pautadas pelo interesse público, apostando em um modelo de jornalismo sem fins lucrativos, como forma de garantir a independência. Delimitou-se à autoria feminina por considerar relevante a participação das jornalistas mulheres na história do jornalismo investigativo e por essa participação ser pouco difundida tanto na academia quanto no mercado.

Diferente da concepção que defende que toda prática jornalística é investigativa, o artigo aponta que as transformações pelas quais o jornalismo passou entre os séculos $X X$ e XXI, impulsionadas pelas mudanças sociais e tecnológicas, desenvolveram procedimentos de apuração mais sofisticados, mais dependentes de um trabalho em equipe e, muitas vezes, multidisciplinar. Isso demanda um processo de produção guiado por outra variável de tempo/espaço. Em consonância com Sequeira (2005), o jornalismo investigativo 


\section{Obrevisto \\ ISSN n² 2447-4266 \\ Vol. 1, n 1, Maio-Agosto. 2015 \\ DOI: http://dx.doi.org/10.20873/uft.2447-4266.2015v1n1p18}

se diferencia porque demanda de métodos de pesquisa e estratégias operacionais. No jornalismo investigativo a informação é algo susceptível de ser "trabalhado mais a fundo, de ser documentado, ampliado, verificado, contextualizado, indagado e investigado sob todos os ângulos" (LOPES, PROENÇA, 2003, p. 10).

Nesse sentido, entende-se que o jornalismo investigativo constitui um dos gêneros do jornalismo, delimitando cada vez mais suas especificidades e complexidade a partir da disponibilização de informações na sociedade digital, globalizada e democrática e, paralelamente, amparado e resguardado pelo acesso legal às informações. ${ }^{4}$ Isso não significa que há uma maior facilidade ou mesmo transparência na obtenção das informações, ainda hoje depara-se com sonegação de dados, censura e violência contra jornalistas ${ }^{5}$. Tampouco pode-se considerar que procedimentos de apuração que exigem maior rigor, investigação e sistematização são filhos da contemporaneidade e da sociedade em rede, contudo a prática investigativa se fortalece ao longo do século $X X$ em diferentes países.

Kovach e Rosenstiel (2003) mostram que conforme essa prática amadureceu, surgiram três desdobramentos: reportagem investigativa original, reportagem investigativa interpretativa e reportagem sobre investigações. Essas formas demandam procedimentos próprios de investigação e apuração. A primeira caracteriza-se pela atuação dos repórteres na descoberta dos dados e informações até então não revelados. Esse tipo, segundo os autores, normalmente culmina em investigações públicas oficiais sobre o que foi

\footnotetext{
${ }_{5}^{4}$ Um exemplo é a Lei de Acesso à Informação - LAl, no 12.527/2011

5 Relatório da UNESCO, divulgado pela ABRAJI (Associação Brasileira de Jornalismo Investigativo) aponta que entre 2011 e 2013, 276 jornalistas de diferentes nacionalidades foram mortos, sendo que 37 deles atuavam em jornalismo online. Outro problema é a violação e ameaças à liberdade de expressão, como revela o Relatório Anual 2014 - Violação à Liberdade de Expressão, também divulgado pela ABRAJl, o qual analisa 55 casos ocorridos no Brasil contra comunicadores e defensores dos direitos humanos.
} 


\section{Obrevisto \\ ISSN n² 2447-4266 \\ Vol. 1, n 1, Maio-Agosto. 2015 \\ DOI: http://dx.doi.org/10.20873/uft.2447-4266.2015v1n1p18}

noticiado. A segunda forma é agrupada por Nascimento (2010) junto com o primeiro tipo, ao colocar as duas como resultado da habilidade do trabalho de investigação do repórter. Nessa concepção é mérito do repórter analisar, buscar, cruzar informações e encontrar irregularidades, bem como, olhar cautelosamente para os dados sob um novo viés até então não revelado. $\mathrm{A}$ terceira forma corresponde ao acompanhamento por parte do repórter nas investigações oficiais em andamento, seja da Polícia Federal, promotoria ou agências governamentais. São processos sob investigação. Para Nascimento (2010), essa última classificação não constitui jornalismo investigativo, pois diferente das anteriores, não foi o repórter quem descobriu as irregularidades. $\mathrm{O}$ autor reitera seu posicionamento fazendo referência à própria nomenclatura: reportagem sobre investigações.

O estudo aqui proposto segue a mesma metodologia elaborada por Nascimento (2010), ou seja, também entende-se que a reportagem sobre investigação não se trata de uma reportagem investigativa. Porém, concebe que o processo de investigação oficial e a cobertura jornalística contínua de um acontecimento não precisam necessariamente caminhar no mesmo compasso.

\section{Reportagens investigativas, registros históricos e a participação feminina}

O termo reportagem investigativa é cunhado em 1964, nos EUA, quando o prêmio Pulitzer categoria reportagem foi para o jornal Philadelphia Bulletin, que denunciou por meio de uma série de textos jornalísticos a corrupção de oficiais da corporação policial envolvidos em uma rede de "jogatina" na cidade de Philadelphia. A nova categoria Reportagem Investigativa veio substituir a Reportagem Local (KOVACH, ROSENSTIEL, 2004). Não se pode afirmar categoricamente que o termo não tenha sido usado anteriormente em outro país. Como pontua Nascimento (2010) há muita informação sistematizada sobre o conhecimento jornalístico no ocidente, talvez 


\section{Obrevisto \\ ISSN n² 2447-4266 \\ Vol. 1, n 1, Maio-Agosto. 2015 \\ DOI: http://dx.doi.org/10.20873/uft.2447-4266.2015v1n1p18}

isso ocorra devido à facilidade de entendimento da língua inglesa e à dificuldade de entendimento de outras línguas na busca de encontrar material bibliográfico. Entretanto, pode-se afirmar que a prática de denúncia já ocorria antes do século XX em outras localidades e mesmo nos EUA.

Ainda em 25 de setembro de 1690, Benjamin Harris denunciou a violência dos índios norte-americanos contra soldados franceses e criticou "a aliança da Grã-Bretanha com os índios" (NASCIMENTO, 2010, p.33), na única edição do jornal americano de Boston Publick Occurrences. Em 1721, James Franklin fez uma série de denúncias no jornal americano New England Courant contra as autoridades religiosas que cometeram erros em um programa de vacinação contra varíola em Boston, espalhando a doença entre a população (NASCIMENTO, 2010, p.33).

Burgh (2008) mostra que Emile Zola adicionou técnicas de observação para denunciar as condições de vida, pobreza e miséria na França causadas pela revolução industrial em seus textos no século XIX. Mais tarde, esse método de observação cautelosa ficou denominado como documentary realism por Keating (1991), e passou a ser utilizado no jornalismo investigativo na busca da imparcialidade da informação. Assim como Zola, Charles Booth também utilizou desse método de observação em suas obras Life and labour of the people of London $^{6}$ publicadas entre 1889 e 1891. E no mesmo século alguns anos antes desse período, o texto de cinco páginas do jornalista W.T. Stead intitulado The Violation of Virgin's, The report off our secret commission, ${ }^{7}$ publicado no jornal londrino Pall Mall Gazette, em 6 de julho de 1885, denunciou a prostituição infantil envolvendo a venda de meninas em Bordéis de Londres ${ }^{8}$. A repercussão gerou debate público e resultou na emenda da Lei Criminal proibindo o

\footnotetext{
${ }^{6}$ Vida e o trabalho do povo em Londres (tradução nossa).

${ }^{7}$ A violação da virgem, o relatório da nossa comissão secreta (tradução nossa).

${ }^{8} \mathrm{O}$ jornalista também apresentou as investigações de uma comissão sobre abusos e tráfico de jovens.
} 


\section{Obsevisto \\ ISSN n² 2447-4266 \\ Vol. 1, n 1, Maio-Agosto. 2015 \\ DOI: http://dx.doi.org/10.20873/uft.2447-4266.2015v1n1p18}

comércio sexual de crianças e elevando a idade do consentimento de 13 para 16 anos (BURGH, 2008).

Sobre a participação das mulheres na produção de reportagens investigativas, a revisão bibliográfica traz dados referente ao século XIX, nos EUA, talvez aqui também a informação esbarre nos limites da língua. Entre as pioneiras destacou-se Margaret Fuller, correspondente na Europa do New Yourk Tribune, na década de 1840 (entre 1842 e 1847), e editora do jornal literário The Dial, que escrevia sobre prostituição, doenças mentais e prisões, e sua contemporânea Anne Royal que reportou sobre fraudes federais e roubo de terras indígenas por parte do governo americano nos jornais Washingthon Paul Pray e The Huntress (SILVEIRINHA, 2007). Embora o número de jornalistas mulheres fosse pequeno nos EUA, a participação aumentava a cada ano. Segundo Chambers, Steiner e Fleming (2004), em 1880, dos 12.308 jornalistas empregados nos EUA, 288 eram mulheres. Costa (2013) mostra que de acordo com a revista The Journalist, em 1886, 500 mulheres trabalhavam com regularidade na parte editorial dos jornais americanos e que em 1888, só nos jornais de Nova lorque, elas somavam 200.

De acordo com a autora, o que impulsionou a participação feminina no jornalismo foi o chamado stunt girl, ou o uso do disfarce, uma estratégia adotada pelas jornalistas no final do século XIX. "[...] o advento das stunt girls e as amplas seções dedicadas às mulheres criaram o primeiro lugar real para as mulheres como membros regulares das equipes dos jornais e como parte importante do mix editorial" (KROEGER, 1994, p. 127 apud COSTA, 2013, p.8). Para a historiadora Jean Marie Lutes essa técnica do disfarce fez com que as repórteres da época utilizassem o próprio corpo como um "canal" para conseguirem "transmitir" a informação, no entanto, na época elas foram "menosprezadas" porque o procedimento performático ia na contramão da lógica da objetividade que vigorava na condução do jornalismo (COSTA, 2013). 


\section{Obsevisto \\ ISSN n² 2447-4266 \\ Vol. 1, n 1, Maio-Agosto. 2015 \\ DOI: http://dx.doi.org/10.20873/uft.2447-4266.2015v1n1p18}

"Atuando, na prática, como as heroínas sensacionais de suas próprias matérias, elas redefiniram a reportagem e usaram seus corpos não apenas como um meio de adquirir a notícia, mas como a própria fonte dela" (LUTES, 2006 apud COSTA, 2013, p. 9).

Um exemplo de stunt girl foi a jornalista Elizabeth Jane Cochran (18641922) que assinava com o pseudônimo Nellie Bly, enquanto trabalhou no New York World, de Joseph Pulitzer, durante o final da década de 1880 e 1896, com um intervalo entre 1890 e 1893. Uma das suas primeiras reportagens publicadas foi sobre os dez dias que passou se fingindo de "louca" em um manicômio de Nova lorque para descobrir como era o tratamento realizado com os pacientes (COSTA, 2013).

No início do século $X X$, constituiu-se no jornalismo o "municipal housekeeping", que seria o "trabalho doméstico municipal", um movimento de denúncia na imprensa feminina americana de temas que afetavam mulheres e crianças, relacionados a saúde, higiene, emprego, condições de vida e trabalho infantil. "...baseava-se na ideia progressista de que os valores domésticos das mulheres podiam ser estendidos à cidade e que por isso seria da responsabilidade delas manter as cidades seguras e limpas, contribuindo assim para o fim da corrupção da vida pública" (SILVEIRINHA, 2007, p.120). Hellen Campbell também destacou-se nas reportagens investigativas no início do século XX, com uma série de artigos sobre os bairros de Nova lorque no New York Tribune e, posteriormente, atuou também como muckrakers ${ }^{9}$ (SILVEIRINHA, 2013). Os muckrakers especializaram-se em denunciar as mazelas oficiais e cobrar reformas em âmbito local, estadual e federal (KOVACH \& ROSENSTIEL, 2003). Entre 1902 a 1904, as reportagens muckrakers publicadas na revista americana McClure's Magazine, como The History of Standard Oil Co,

\footnotetext{
${ }^{9}$ Caçadores de estrumes (tradução nossa).
} 


\section{Obsevisto \\ ISSN n² 2447-4266 \\ Vol. 1, n 1, Maio-Agosto. 2015 \\ DOI: http://dx.doi.org/10.20873/uft.2447-4266.2015v1n1p18}

de Ida Tarbell, conhecida na redação como "um dos garotos", reportou as práticas ilícitas das empresas de John Rockfeller. Mas além dela, uma geração de jornalistas, adotaram uma investigação meticulosa e expuseram o poder corrupto nacional e local envolvendo abusos de trabalho infantil, oligopólio do petróleo e sua relação com a ferrovia. Entre essa geração sobressaem: Lincoln Stevens com a série publicada, em 1904, Shame of the Cities (KOVACH \& ROSENSTIEL, 2003); e no mesmo ano, Upton Sinclair que usou do disfarce para denunciar a falta de higiene em uma indústria de carne; além dos impressos Public Opinion que divulgou 66 mil acidentes com morte de operários em 1905 e Cosmopolitan com a denúncia de corrupção em seguradoras em 1905 e 1906 (NASCIMENTO, 2010).

Já no Brasil, em novembro de 1923, o jornal carioca Correio da Manhã publicou um texto acusando o então presidente Epitácio Pessoa de ter favorecido exportadores de açúcar em troca de uma joia para sua mulher (NASCIMENTO, 2010). De acordo com o estudioso Juarez Bahia (apud NASCIMENTO, 2010), na década de 1940, a revista O Cruzeiro, comandada pelo jornalista Assis Chateaubriand, produziu reportagens de caráter investigativo. E no mesmo contexto, no fim da década de 1940, no governo de Getúlio Vargas, o jornal O Estado de S.Paulo denunciou uma operação irregular com o Banco do Brasil na tentativa de criar o monopólio no mercado de algodão (NASCIMENTO, 2010). No contexto das denúncias e revelações, a repórter de geral Hellen Alves destacou-se nos Diários Associados, durante os anos de 1960, com uma série de reportagens sobre a prostituição em São Paulo. E em 1967, Hellen foi enviada pelo jornal com o repórter fotográfico Antonio Moura para realizarem a cobertura da Operação Bolívia, referente ao julgamento do francês Régis Debray em Carmiri, na Bolívia. Ao descer em Santa Cruz de La Sierra, ela percebeu uma movimentação por parte do exército na região em busca de Che Guevara. Como chegaram alguns dias antes do julgamento, 


\section{Obsevisto \\ ISSN n² 2447-4266 \\ Vol. 1, n 1, Maio-Agosto. 2015 \\ DOI: http://dx.doi.org/10.20873/uft.2447-4266.2015v1n1p18}

deslocaram-se para cobrir a morte de quatro guerrilheiros em Valle Grande (RIBEIRO, 1998). A repórter percebeu pelos rostos que não eram camponeses bolivianos mas sim argentinos e oficiais cubanos, como ela mesma afirma para o jornalista José Hamilton Ribeiro (RIBEIRO, 1997). Em seguida, a equipe consegue cavar uma autorização e recursos para acompanhar a chegada de mais um corpo, desta vez era Che Guevara. Hellen enviou o texto por telex militar e na mesma madrugada retornou para São Paulo com a reportagem completa. O texto de Helle e a foto de Moura foram publicados no Diário da Noite em 11 de outubro de 1967 (RIBEIRO, 1997). O sucesso da cobertura ocorreu devido sua perspicácia em perceber o que estava ocorrendo, observação dos movimentos da comunidade e do exército, atenção às conversas e insistência em acompanhar os passos oficiais.

Na década de 1950, o jornalista argentino Rodolfo Walsh desenvolveu métodos de apuração e checagem de informações precisos e elaborados, confrontando dados, para investigar a suspeita de um fuzilamento clandestino realizado pela polícia argentina em junho de 1956, contra 12 pessoas. O resultado do trabalho de Walsh consagrou a obra Operação Massacre, com três edições diferentes, ao longo de 20 anos, acrescentando prólogos e notas de atualização numa busca incansável de dados sobre a ditadura argentina (WALSH, 2010).

Nos EUA após a Segunda Guerra Mundial, repórteres como Wallace Turner, William Lambert e George Bliss impulsionam a prática investigativa ao perseguirem e denunciarem corrupção. Em 1972 ocorre o caso Watergate, resultado do trabalho dos jornalistas Bob Woodward e Carl Bernstein, envolvendo o então presidente Richard Nixon e a CIA na invasão de um comitê do Partido Democrático (KOVACH \& ROSENSTIEL, 2003). Antes do Watergate, em 1962 Rachel Carson revela em seu livro Silent Spring "os efeitos de envenenamento de pesticidas" (KOVACH \& ROSENSTIEL, 2003, p.177) e em 


\section{Obsevisto \\ ISSN n² 2447-4266 \\ Vol. 1, n 1, Maio-Agosto. 2015 \\ DOI: http://dx.doi.org/10.20873/uft.2447-4266.2015v1n1p18}

1969, outro texto emblemático envolvendo investigação foi a cobertura do jornalista freelancer Seymour Hersh sobre o massacre de My Lai, em que pelo menos 109 civis foram mortos por militares americanos, durante a guerra contra o Vietnã (NASCIMENTO, 2010). Nesse período surgem nos EUA entidades que patrocinam reportagens investigativas como o Fund for Investigative Journalism em 1969 e que representam a categoria como Investigative Reporters and Editors (IRE) (NASCIMENTO, 2010).

No Brasil, apesar do governo militar e da censura, entre 1964 a 1984 foram realizadas reportagens de denúncias, por segmentos como a revista Realidade da editora Abril, jornal Estado de S.Paulo e por veículos alternativos. "Basta, por exemplo, ver a lista de vencedores do Prêmio Esso entre 1964 a 1984 para se observar que houve nesses anos muitas reportagens com denúncias exclusivas" (NASCIMENTO, 2010, p.42). No jornal Estado de S.Paulo, sob a coordenação de Ricardo Kotsho, foi realizada a série de reportagens "Assim vivem os nossos superfuncionários" revelando as boas condições de vida dos ministros e alto funcionários do governo, em 1976 durante o governo do general Ernesto Geisel, após o fim da censura prévia (SEQUEIRA, 2005). Segundo Porto (1996 apud NASCIMENTO, 2010) o jornalismo investigativo fortalece no Brasil somente com a Nova República, após o fim da ditadura militar.

Esse breve relato histórico mapeando algumas reportagens investigativas que marcaram o jornalismo americano, inglês, brasileiro e argentino, não tem a pretensão de esgotar tudo o que foi produzido nesses países e sim apontar a necessidade de investigar e apurar mais sobre o tema, enfatizando que não foi o Watergate o marco da prática de reportagens investigativas. Antes já se pautavam no jornalismo denúncias sociais, políticas e econômicas. O relato busca também dar visibilidade ao trabalho das mulheres 


\section{Obsevisto \\ ISSN n² 2447-4266 \\ Vol. 1, n 1, Maio-Agosto. 2015 \\ DOI: http://dx.doi.org/10.20873/uft.2447-4266.2015v1n1p18}

jornalistas que atuaram em reportagens investigativas ${ }^{10}$ e mostrar como se faz necessário escavar informações sobre a participação feminina, que ainda encontra-se dispersa nas referências bibliográficas as quais dialogam transversalmente com esta temática.

\section{Sobre a Agência Pública, o corpus da pesquisa}

Agência Pública aposta num modelo de jornalismo sem fins lucrativos para manter a independência, com a missão de produzir "reportagens de fôlego" pautadas pelo interesse público, visando ao fortalecimento do direito à informação, à qualificação do debate democrático e à promoção dos direitos humanos. Todas as reportagens são feitas com base em técnicas de apuração do jornalismo investigativo. Além de produzir, a Pública atua na promoção do jornalismo investigativo independente, por meio de programas de mentorias para jovens jornalistas, bolsas de reportagem e incubação de projetos inovadores de jornalismo independente. No caso das reportagens analisadas aqui, todas se enquadram no programa de mentorias.

A escolha das reportagens do site como objeto de análise dessa pesquisa se dá justamente pela proposta da Pública na produção de jornalismo investigativo no Brasil, oferecendo um conteúdo com apuração em profundidade, trazendo os contextos e suas implicações. Nesse caso, o processo de apuração e a metodologia de investigação não são atravessados por fatores do jornalismo diário, como tempo limitado e interferência de interesses comerciais, bem como o formato na internet garante espaço para que as informações sejam apresentadas em toda sua complexidade, apostando em recursos como galeria de fotos, imagens, áudio, vídeos e infográficos.

\footnotetext{
${ }^{10}$ O International Women's Media Foundation (Iwmf) destina um fundo de apoio a mulheres jornalistas que queiram também desenvolver reportagens investigativas.

http://www.coletiva.net/noticias/2015/02/premiacao-incentiva-novos-projetos-de-jornalistasmulheres/
} 


\title{
Obrevisto
}

ISSN n² 2447-4266

Vol. 1, n 1, Maio-Agosto. 2015

DOI: http://dx.doi.org/10.20873/uft.2447-4266.2015v1n1p18

Além da produção de reportagens investigativas, a Pública vem também conseguindo inserir seus conteúdos em espaços de mídia tradicionais, como impressos tradicionais que vivem do jornalismo diário, como explica a jornalista Natália Viana, uma das fundadoras da Agência:

\begin{abstract}
Porque somos a Agência Pública? O conceito é o seguinte: somos uma agência de reportagens, nós produzimos reportagens e tudo que publicamos é em creative commons, é disponibilizado. Hoje, temos uma rede de republicadores, inclusive grandes jornais tradicionais. Eles precisam de jornalismo e não têm capacidade de fazer. A Pública é como uma estante de reportagem. É para os veículos irem lá e pegarem. Mas veja que veículos são também pessoas, blogs, perfis no Facebook. Todos são emissores hoje em dia. (OBSERVATÓRIO DA IMPRENSA, 2012)
\end{abstract}

Outro diferencial da Agência Pública é o espaço garantido por profissionais mulheres. O projeto foi lançado pelas jornalistas Natália Viana e Marina Amaral, que seguem na direção. Além disso, a maior parte da equipe de reportagem é constituída por jornalistas mulheres. São dois repórteres para três jornalistas mulheres, uma coordenadora de comunicação e duas diretoras. Com o financiamento de bolsas para a produção de reportagens independentes, a Agência Pública possibilita uma maior participação feminina no espaço de produção em jornalismo investigativo. ${ }^{11}$ As quatro reportagens selecionadas para análise nesse artigo foram produzidas por bolsistas financiadas pela agência. Em 2014, a Agência Pública teve nove reportagens premiadas nacionalmente: quatro delas de autoria exclusivamente feminina, três foram produzidas por profissionais de ambos os sexos e duas produzidas exclusivamente por homens.

\footnotetext{
${ }^{11}$ Embora em números absolutos existam mais mulheres atuando como jornalistas, o número de mulheres empregadas nos impressos é menor, não chega a 50\%. Dados da RAIS (2013) referente ao setor formal da profissão com contrato da CLT e regime formal de trabalho, revelam que as mulheres representam $45,42 \%$ do mercado nacional. Ou seja, há uma parcela considerável de mulheres em situações precárias de trabalho no setor informal da profissão (freelancer, PJ) (LEITE, 2015).
} 


\section{Obsevisto \\ ISSN n² 2447-4266 \\ Vol. 1, n 1, Maio-Agosto. 2015 \\ DOI: http://dx.doi.org/10.20873/uft.2447-4266.2015v1n1p18}

\section{Classificação e caracterização}

As reportagens analisadas são: "Dor em dobro"12" (29/05/14); "Severinas: as novas mulheres do sertão" (30/04/14), e "Quanto mais presos, maior o lucro"15" (27/05/14). A classificação das fontes seguiu a proposta de Schmitz (2011): categoria, grupo e crédito. $\mathrm{Na}$ 'categoria', as fontes dividem-se entre primárias e secundárias. São primárias aquelas fontes que estão diretamente envolvidas aos fatos, que fornecem a essência da reportagem. As fontes secundárias são aquelas que contextualizam e complementam as informações que foram apresentadas pelas fontes primárias. Há uma adaptação na classificação das fontes no que se refere à categoria. Devido a complexidade de informações nas reportagens investigativas, foi acrescentada a definição de importância que Pereira Junior (2006) dá aos personagens do acontecimento jornalístico. As fontes primárias foram divididas naquelas que são fulcrais, cuja reportagem não existe sem elas, e as primárias de média importância.

Na classificação 'grupo', também segue a divisão de Schmitz (2011). Por fonte oficial, entende-se alguém em função ou cargo público e se pronuncia por órgãos do Estado. Como empresarial, compreende aquela fonte que representa corporação empresarial, seja indústria, comércio ou serviços. Institucional é aquela fonte que responde por uma organização sem fins lucrativos ou grupo social. A fonte popular é aquela que aparece como vítima de determinada situação, que fala por si mesma, diferente da fonte testemunhal, que fala sobre o que viu acontecer com outro. A fonte especializada é aquela que apresenta um saber específico ou reconhecido, geralmente relacionada a alguma profissão ou área de atuação. A fonte

\footnotetext{
${ }^{12}$ http://apublica.org/2014/05/dor-em-dobro-2/

${ }^{13} \mathrm{http}$ ///apublica.org/2013/08/severinas-novas-mulheres-sertao/

${ }_{15} \mathrm{http}$ ://apublica.org/2014/04/em-guerra-contra-a-nestle/

${ }^{15} \mathrm{http}$ ://apublica.org/2014/05/quanto-mais-presos-maior-o-lucro/
} 


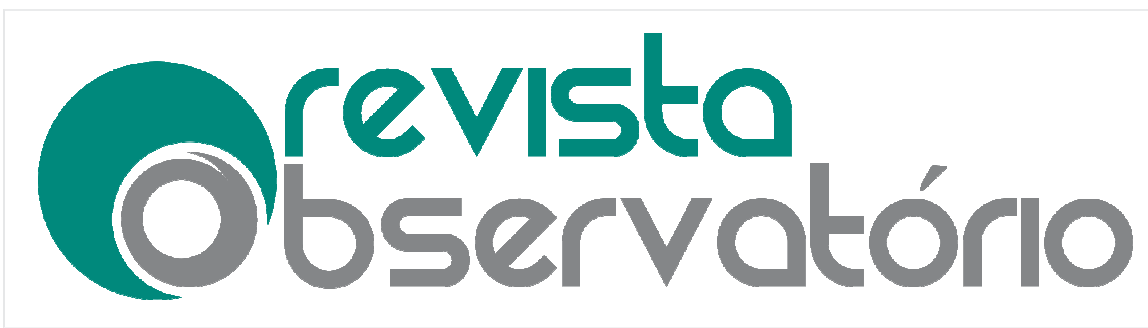

ISSN n² 2447-4266

Vol. 1, n 1, Maio-Agosto. 2015

DOI: http://dx.doi.org/10.20873/uft.2447-4266.2015v1n1p18

referencial é definida como qualquer bibliografia ou documentos que são usados na constituição da reportagem.

Quanto ao 'crédito', o artigo usa a classificação de Sousa (2001), que divide as fontes da reportagem em on the record, on background, on deep background e off the record. Isso porque as reportagens investigativas contam com uma variedade de fontes maior que a classificação entre 'identificada' ou 'anônima'.

On the record (atribuição directa, para publicação) - A fonte é identificada e tudo o que ela profere pode ser objeto de enunciação jornalística. É a regra comum e aquela que deve ser usada quando a fonte não pede confidencialidade. On Background/not for attribution (atribuição com reserva) - A fonte não é totalmente identificada, embora sejam dadas algumas pistas superficiais sobre os meios em que ela se movimenta. [...] On deep background (atribuição com reserva total) - Não só a fonte não é identificada como também não pode ser referido o meio em que ela se movimenta, embora as informações fornecidas pela fonte possam ser difundidas. [...] Off the record (confidência total) - A fonte não pode ser identificada e a informação que ela fornece não pode ser divulgada. Contudo, esta informação auxilia, frequentemente, o trabalho do jornalista. (SOUSA, 2001, p. 67-68)

Como a análise partiu principalmente do resultado da apuração jornalística apresentado nas reportagens publicizadas, não foi possível identificar no texto, por exemplo, as fontes on deep background e off the record.

\section{Reportagem Dor em dobro}

Com autoria de Beatriz Souza, Gabriela Sá Pessoa, Natacha Cortêz, a reportagem é classificada como investigativa original. Trata-se de uma denúncia sobre a dificuldade no acesso de mulheres vítimas de violência sexual ao direito ao aborto legalizado, em hospitais da rede pública de saúde credenciados para o serviço. A reportagem interpreta dados e números sobre o caso, cruzando 


\section{Obsevisto \\ ISSN n² 2447-4266 \\ Vol. 1, no 1, Maio-Agosto. 2015 \\ DOI: http://dx.doi.org/10.20873/uft.2447-4266.2015v1n1p18}

informações de ocorrência de violência sexual, abortos clandestinos e baixo número de abortos legalizados registrados nos hospitais credenciados. A reportagem ainda traz o relato de duas vítimas, contextualizando a falha na aplicação de políticas públicas com a fala de 23 fontes especializadas, referenciais, institucionais e oficiais, num texto com 55 mil caracteres. As informações são trabalhadas em 11 intertítulos, 2 gráficos e 4 ilustrações de mulheres evitando identificar as personagens fulcrais e primárias.

Quadro 1. Classificação das fontes por categoria

\begin{tabular}{|l|c|}
\hline Categoria & Número de fontes \\
\hline Primária (fulcral) & 2 \\
\hline Primária (média importância) & 6 \\
\hline Secundárias & 17 \\
\hline TOTAL & $\mathbf{2 5}$ \\
\hline
\end{tabular}

Quadro 2. Classificação das fontes por grupo

\begin{tabular}{|l|c|}
\hline Grupo & Número de fontes \\
\hline Oficial & 7 \\
\hline Institucional & 6 \\
\hline Popular & 2 \\
\hline Especializada & 4 \\
\hline Referencial & 6 \\
\hline TOTAL & $\mathbf{2 5}$ \\
\hline
\end{tabular}

Dentre 25 fontes, apenas duas delas foram classificadas como primárias fulcrais, pois mais de $50 \%$ das informações contidas no texto são fundamentas nestas falas: uma mulher que fez $\mathrm{o}$ aborto legal e relata sua experiência em obter o atendimento público; e o médico Jefferson Drezet, profissional referência na realização de abortos legais no Brasil. Chama atenção a disparidade entre o número de fontes primárias com 0 de fontes para contextualização da pauta. Com relação ao grupo, a maioria das fontes se enquadra em oficiais, como do Ministério da Saúde e da Secretaria de Políticas Públicas para as Mulheres, na cobrança pelas falhas na execução da política 


\section{Obrevisto \\ ISSN n² 2447-4266 \\ Vol. 1, no 1, Maio-Agosto. 2015 \\ DOI: http://dx.doi.org/10.20873/uft.2447-4266.2015v1n1p18}

pública. O número de fontes institucionais e referenciais está equilibrado, são seis em cada. A reportagem investigativa traz no cruzamento das informações dados de pesquisas, leis e documentos. Entretanto, por se tratar de um extenso material expondo a dificuldade das mulheres em acessarem o direito ao aborto, apenas duas das 25 fontes da reportagem são vítimas do sistema. São elas também as duas únicas fontes da reportagem classificadas como on background, enquanto todas as outras aparecem como on the record.

\section{Reportagem Severinas: as novas mulheres do sertão}

A reportagem de Eliza Capai é classificada como original, pois traz uma análise dos dados oficiais do programa do Governo Federal Bolsa Família e as transformações sociais que ocasionou na condição e qualidade de vida das mulheres que recebem o benefício e vivem no Piauí, na cidade de Guaribas, a dez horas da capital Teresina. O texto apresenta relatos de seis mulheres que conseguiram alcançar maior autonomia em decorrência do valor garantido pelo benefício social. A reportagem ainda relaciona essa conquista com outros índices, como o de maior participação de crianças e adolescentes nas escolas. $O$ texto tem aproximadamente 11 mil caracteres e traz quatro fotografias das fontes entrevistadas e familiares e um minidoc com as mesmas informações da reportagem.

Quadro 3. Classificação das fontes por categoria

\begin{tabular}{|c|c|}
\hline Categoria & Número de fontes \\
\hline Primária (fulcral) & 5 \\
\hline $\begin{array}{c}\text { Primária (média } \\
\text { importância) }\end{array}$ & 1 \\
\hline Secundárias & 4 \\
\hline TOTAL & $\mathbf{1 0}$ \\
\hline
\end{tabular}




\section{Obsevisto \\ ISSN n² 2447-4266 \\ Vol. 1, n 1, Maio-Agosto. 2015 \\ DOI: http://dx.doi.org/10.20873/uft.2447-4266.2015v1n1p18}

Quadro 4. Classificação das fontes por grupo

\begin{tabular}{|l|c|}
\hline Grupo & Número de fontes \\
\hline Oficial & 1 \\
\hline Popular & 6 \\
\hline Testemunhal & 2 \\
\hline Especializada & 1 \\
\hline TOTAL & $\mathbf{1 0}$ \\
\hline
\end{tabular}

A reportagem é baseada principalmente no cruzamento das informações obtidas pelos relatos de algumas mulheres com os índices de uma pesquisa sobre o Bolsa Família na região. As fontes fulcrais representam metade do número de fontes usados na construção do texto, cinco. São relatos simples, como a possibilidade de ter independência sobre seu dinheiro e não precisar manter um casamento infeliz em nome do sustento, antes provido apenas pelo marido. Como fonte primária de média importância aparece a pesquisadora responsável pelo levantamento dos índices utilizados na análise da repórter. Como fontes secundárias, a reportagem traz o delegado da cidade, que comenta sobre a ocorrência de casos de violência doméstica na região e o novo cenário de independência das mulheres.

O delegado é também a única fonte oficial usada e o relato das mulheres beneficiárias do auxílio se enquadra em 'popular'. Um dos homens líderes na região e também uma familiar, ambos secundários, estão na categoria 'testemunhal', porque falam das transformações que estão testemunhando. Todas as mulheres entrevistadas são identificadas no texto, somente o delegado e essa pessoa da família se enquadram na classificação on background. A reportagem ainda traz informações de uma apuração de campo, 


\section{Obsevisto \\ ISSN n² 2447-4266 \\ Vol. 1, no 1, Maio-Agosto. 2015 \\ DOI: http://dx.doi.org/10.20873/uft.2447-4266.2015v1n1p18}

mencionando "de acordo com o relato das mulheres", mas sem atribuir a ninguém as informações apresentadas, também background.

\section{Reportagem Em guerra contra a Nestlé}

A reportagem de Marina Almeida é original e trata da exploração da empresa Nestlé de uma nascente na cidade de São Lourenço, no interior de Minas Gerais, para a comercialização de água mineral. $\mathrm{O}$ texto ainda traz o relato de moradores que se mobilizaram contra a exploração da empresa. Além da preocupação ambiental com as consequências que a exploração pode trazer, a crença local também credita nas águas de São Lourenço algumas propriedades curativas. O texto conta com cerca de 28 mil caracteres, cinco fotos do local e um gráfico.

Quadro 5. Classificação das fontes por categoria

\begin{tabular}{|l|l|}
\hline Categoria & Número de fontes \\
\hline Primária (fulcral) & 5 \\
\hline Primária (média importância) & 5 \\
\hline Secundárias & 5 \\
\hline TOTAL & $\mathbf{1 5}$ \\
\hline
\end{tabular}

Quadro 6. Classificação das fontes por grupo

\begin{tabular}{|l|c|}
\hline Grupo & Número de fontes \\
\hline Oficial & 7 \\
\hline Empresarial & 1 \\
\hline Institucional & 3 \\
\hline Especializada & 3 \\
\hline Referencial & 1 \\
\hline TOTAL & $\mathbf{1 5}$ \\
\hline
\end{tabular}




\title{
Obrevisto \\ ISSN n² 2447-4266 \\ Vol. 1, n 1, Maio-Agosto. 2015 \\ DOI: http://dx.doi.org/10.20873/uft.2447-4266.2015v1n1p18
}

$\mathrm{Na}$ classificação em categoria, as fontes ficaram bem divididas nessa reportagem. Entre as fulcrais estão líderes de movimento contra a exploração das águas e promotores públicos responsáveis pela investigação do caso. As fontes oficiais são as que aparecem em maior número, como representantes de secretarias e órgãos ligados ao meio ambiente. Como fonte empresarial tem apenas a Nestlé. Em questionário enviado por e-mail em 26/05/2015, a jornalista relatou que foram consultadas ainda mais fontes, porém foram descartadas no material final.

\begin{abstract}
A maior dificuldade foi para entrevistar a Nestlé, que só respondeu a algumas perguntas por e-mail e não respondeu a algumas questões alegando sigilo comercial, cancelou a visita à fábrica e também não divulgou um estudo que realizou na região. Também foi difícil conversar com os deputados envolvidos na comissão do novo Código de Mineração, apenas o presidente da Comissão falou comigo. O DNPM também não colaborou com entrevistas, apesar das inúmeras tentativas, e só respondeu às questões enviadas pela Lei de Acesso à Informação. Acredito que foram cerca de 30 entrevistas. Também descartei a entrevista de um segundo vereador e de um funcionário da secretaria de Turismo, porque não acrescentavam nada às outras entrevistas citadas na matéria. O critério foi esse: o que as entrevistas tinham a acrescentar à discussão. (Autora da reportagem)
\end{abstract}

Sobre o processo investigativo, a jornalista ainda relata que a reportagem não partiu da investigação do Ministério Público sobre o caso, mas que o material foi usado para embasar as informações obtidas através dos moradores e outros envolvidos com a exploração das águas naturais da cidade. Nesta reportagem, todas as fontes utilizadas foram identificadas no material final.

\section{Reportagem Quanto mais presos, maior o lucro}

A reportagem de Paula Sacchetta é original e fala sobre uma prisão com administração no modelo PPP - Parceria Público-Privado, em Ribeirão das Neves, interior do estado de Minas Gerais. O texto cruza informações da fala de especialistas e outras referências documentais e denuncia o modelo carcerário 


\section{Obsevisto \\ ISSN n² 2447-4266 \\ Vol. 1, no 1, Maio-Agosto. 2015 \\ DOI: http://dx.doi.org/10.20873/uft.2447-4266.2015v1n1p18}

privado, no qual o maior número de presos representa mais lucro para a empresa gestora, pois são mão-de-obra baratas. A denúncia é que isso tenderia a aumentar o número de pessoas encarceradas. Fontes internas e externas a penitenciária relatam corte de custos na manutenção dos presos que representa condições de vida desumanas, como poucos minutos de banho de sol e corte de água para reduzir o tempo nos chuveiros. A crítica também aparece na terceirização do serviço, com a responsabilidade punitiva do Estado sendo transferida para uma empresa gestora que espera obter retorno financeiro com o investimento. $\mathrm{O}$ texto tem aproximadamente 19 mil caracteres, duas fotos sem identificação da penitenciária, um infográfico e um minidoc.

Quadro 7. Classificação das fontes por categoria

\begin{tabular}{|l|c|}
\hline Categoria & Número de fontes \\
\hline Primária (fulcral) & 6 \\
\hline Primária (média importância) & 3 \\
\hline Secundárias & 4 \\
\hline TOTAL & $\mathbf{1 3}$ \\
\hline
\end{tabular}

Quadro 8. Classificação das fontes por grupo

\begin{tabular}{|l|c|}
\hline Grupo & Número de fontes \\
\hline Oficial & 2 \\
\hline Empresarial & 2 \\
\hline Institucional & 1 \\
\hline Testemunhal & 3 \\
\hline Especializada & 4 \\
\hline Referencial & 1 \\
\hline TOTAL & $\mathbf{1 3}$ \\
\hline
\end{tabular}




\section{Obsevisto \\ ISSN n² 2447-4266 \\ Vol. 1, n 1, Maio-Agosto. 2015 \\ DOI: http://dx.doi.org/10.20873/uft.2447-4266.2015v1n1p18}

Quase metade das fontes foram classificadas como fulcrais. São principalmente especialistas que acompanham o caso da penitenciária privada em Ribeirão das Neves e denunciam os riscos que correm os detentos de exploração e más condições. Também aparece como fulcral algumas informações atribuídas à "denúncia de presos", sem identificação direta. Com relação aos grupos, as três fontes testemunhais também são on background e uma on deep backgroun, porque tratam-se de denúncias de detentos, da esposa de um detento e de fontes não identificadas, mas que dão a entender serem pessoas de dentro da penitenciária. A única fonte referencial da reportagem é o contrato entre o Estado e a empresa que administra o local.

\section{Considerações finais}

A análise permitiu identificar que todos os textos se enquadram na classificação de reportagem investigativa original, pois as autoras iniciaram a investigação a partir da cruzamento de dados, mas sem realizar a interpretação de informações. Os textos apresentam pesquisas, dados e documentos, informações oriundas de fontes primárias e secundárias que são cruzadas com as falas oficiais, especialistas, empresariais, institucionais e testemunhais. Com relação à classificação por grupo, das 4 reportagens analisadas, duas trazem fontes de cinco grupos diferentes, uma quatro e outra seis. A reportagem apresenta um conteúdo interpretado, contextualizado, para melhor compreensão por parte do leitor. Na reportagem Dor em Dobro, por exemplo, o texto não se resumiu ao relato apenas de mulher que realizou aborto legalmente. A fala foi costurada com informações como a dificuldade em ter acesso ao serviço, os baixos índices de atendimento e as falhas nas políticas públicas. 


\section{Obsevisto \\ ISSN n² 2447-4266 \\ Vol. 1, n 1, Maio-Agosto. 2015 \\ DOI: http://dx.doi.org/10.20873/uft.2447-4266.2015v1n1p18}

Todas as reportagens foram pautadas por questões de interesse público: aborto legalizado, transformações nas condições de vida em decorrência de benefício social, condições de encarceramento em presídio privado e exploração de recursos naturais por uma empresa multinacional. Os assuntos remetem à políticas públicas, sua aplicação ou a falta delas em diversos setores: saúde, segurança pública, meio ambiente e desenvolvimento humano.

As reportagens são extensas, variando entre 11 mil e 55 mil caracteres. O tamanho dos textos representa um aumento proporcional no número de fontes. Na reportagem Dor em Dobro, o texto com 55 mil caracteres é construído com base em 25 fontes identificadas; em Severinas: as novas mulheres do Sertão são 10 fontes em um texto com 11 mil caracteres; Em Guerra Contra a Nestlé constam 15 fontes em uma reportagem com 28 mil caracteres; e Quanto mais presos maior o lucro conta com 19 mil caracteres, embasada em 13 fontes identificadas.

Entretanto, a quantidade de fontes não necessariamente implica em pluralidade ou profundidade da informação. Com exceção da maior reportagem analisada todos os textos apresentam número maior ou igual entre fontes primárias fulcrais e as de média importância. Na reportagem em questão, com 25 fontes, somente duas dela são fulcrais, sendo seis de média importância e 17 fontes secundárias de contextualização. Nenhuma outra reportagem apresenta número de fontes secundárias superior ao número de fontes primárias (fulcrais e média importância).

A análise ainda revela que, na classificação por grupo, as fontes que mais se sobreassem são as oficiais, institucionais, especializadas, testemunhais e populares, nessa sequência. Chama atenção o fato de reiterar uma prática do jornalismo diário ao trazer mais fontes oficiais na constituição do texto. Como as reportagens são pautadas por questões de interesse público e políticas 


\section{Obrevisto \\ ISSN n² 2447-4266 \\ Vol. 1, n 1, Maio-Agosto. 2015 \\ DOI: http://dx.doi.org/10.20873/uft.2447-4266.2015v1n1p18}

públicas envolvendo denúncias, esperava-se que as falas populares e testemunhais aparecessem em maior número. Somente na reportagem sobre as mulheres do sertão é que as fontes testemunhais sobressaem, superando as fontes oficial e institucional, uma de cada.

$\mathrm{Na}$ reportagem que trata da dificuldade em acessar o atendimento de aborto legalizado, apenas duas fontes testemunhais relatam sua experiência, enquanto são sete fontes oficiais que procuram justificar as falhas na política de saúde pública. Por outro lado, o número de fontes especializadas, que agregam informações complementares, fundamentais para garantir contexto e aprofundamento dos assuntos, aparecem, proporcionalmente, em boas quantidades. A fonte especializada também foi explorada nas reportagens com o propósito de contextualizar o acontecimento rompendo suas particularidades e alinhando-se a dimensões sociais e políticas, travando assim o diálogo entre o fato em si e o fenômeno que o envolve.

\section{Referências bibliográficas}

BURG, H. de. Investigative Journalism. New York, Routledge, 2008.

COSTA, N. Lugar de mulher é na redação. O Jornalismo Performático e o destaque alcançado por repórteres mulheres. In. Seminário Internacional Fazendo Gênero 10 (Anais Eletrônicos), Florianópolis, 2013

CHAMBERS, D., STEINER, L., FLEMING, C. Women and Journalism. New York: Rutledge, 2004.

IMPRENSA Observatório da. Pública - Agência de Reportagem e Jornalismo Investigativo, 2012. Disponível em

<https://www.youtube.com/watch?v=GGj4H71PNYk>

KEATING, P. The Haunted study. London, Fontana, 1991 


\section{Obsevisto \\ ISSN n² 2447-4266 \\ Vol. 1, n 1, Maio-Agosto. 2015 \\ DOI: http://dx.doi.org/10.20873/uft.2447-4266.2015v1n1p18}

KOVACH, B. e ROSENSTIEL, T. Os elementos do Jornalismo. O que os jornalistas devem saber e o público exigir. São Paulo, Geração Editorial, 2004.

LEITE, A. T. B.. Profissionais da mídia em São Paulo: Um estudo sobre profissionalismo, diferença e gênero no jornalismo. São Carlos: UFSCar, 2015. 232p. Tese (Doutorado) - Programa de Pós Graduação em Ciências Sociais, Faculdade de Ciências Sociais da Universidade Federal de São Carlos, São Carlos, 2015.

LOPES, D. F.; PROENÇA, J.L. Jornalismo Investigativo. São Paulo, Publisher Brasil, 2003

NASCIMENTO, S. Os novos escribas. O fenômeno do jornalismo sobre investigações no Brasil. Porto Alegre, Arquipélago Editorial, 2010.

SEQUEIRA, C. M. de. Jornalismo Investigativo: O fato por trás da notícia. São Paulo: Ed. Summus. 2005.

SILVEIRINHA, M. J. Revisitar o passado na América: a "questão de ser mulher" no jornalismo. In: Estudos do Século XX, no 7. p. 115-132: Imprensa da Universidade Coimbra, 2007.

WALSH, R. Operação Massacre. São Paulo, Companhia das Letras, 2010.

Acesse esse e outros artigos da Revista Observatório em:

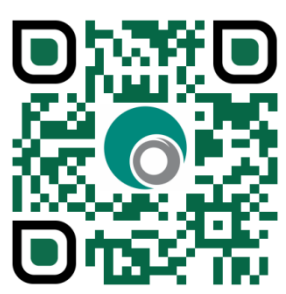

